\title{
Los felices años veinte de Felipe Fox-trot, traducción y creación en la obra de Felipe Pinglo Alva
}

\author{
Rodrigo Sarmiento Herencia \\ rodrigo.sarmiento@unmsm.edu.pe
}

\section{Resumen}

El siguiente artículo trata sobre el impacto que tuvo la música popular estadounidense, particularmente el fox-trot, en la producción de uno de los más importantes personajes de la canción criolla de Lima, Felipe Pinglo Alva. Pese a las fronteras lingüísticas, delimitadas por el desconocimiento del idioma en que llegaban los éxitos cantados que todos querían bailar, el ritmo de moda le propició al compositor barrioaltino un espacio único dentro de su espectro creativo donde pudo verter lo más fresco de su genio literario para así apropiarse y nacionalizar estos nuevos aires que la potencia norteamericana difundió por toda América Latina.

Palabras clave: Felipe Pinglo, música popular limeña, polca, fox-trot, cultura material.

\begin{abstract}
The following paper notices the impact that American popular music, fox-trot in particular, had over Lima's renowned composer Felipe Pinglo Alva. In spite of linguistic limitations, determined by the ignorance of the language in which the greatest hits that everyone wanted to dance were massively distributed, the new rhythm gave the composer a unique space within his creative spectrum where he could bring in a refreshing aspect of his writing that helped him take over the new north American musical genres and assimilate them into Peru's national popular music styles.
\end{abstract}

Keywords: Felipe Pinglo, Peruvian popular music, fox-trot, material culture. 


\section{Los felices años veinte de Felipe Fox-trot, traducción y creación en la obra de Felipe Pinglo Alva}

\section{Introducción}

Hacia la primera década del siglo XX, el espacio sonoro de las capitales y principales ciudades de América Latina sufrió la invasión de un ritmo que fue rápidamente abrazado por la juventud: el fox-trot. Acompañado de múltiples variaciones, tanto musicales como coreográficas, ${ }^{1}$ su expansión a lo largo del cono sur americano se dio antes y durante los procesos de consolidación de los llamados "géneros nacionales" latinoamericanos ${ }^{2}$ —esto es, a lo largo las décadas de 1910, 1920 y 1930 - y su influencia sobre los estilos regionales fue determinante para la modernización de sus músicas populares.

Su presencia como piezas instrumentales puede rastrearse los primeros años de la centuria, como mencionan González y Purcell para el caso chileno; en donde "al menos desde 1905 se editaban en Chile con generosidad partituras de bailes estadounidenses como cakerwalk, one-step, shimmy y foxtrot, algo posible de generalizar a otros países latinoamericanos" (González \& Purcell, 2014, p. 107). Todavía más temprano, en Brasil, se grabaron discos con varios ritmos estadounidenses desde 1903 (Faria, 2011). Pero sería a mediados de la década de 1910 y con mucha más fuerza en 1920 cuando realmente su total adopción como símbolo inequívoco de modernidad en la clase popular se hiciera inevitable y su entrada en el acervo nacional, imparable.

Estados Unidos se había establecido como gran potencia luego de su exitosa participación en la Primera Guerra Mundial. Una década antes de la caída de la bolsa, en su territorio se respiraba verdaderos aires de grandeza que ansiaban la conquista del resto de corrientes eólicas americanas. Pronto su política expansionista entendió que la mejor herramienta para hacerlo era el cine. Ciertamente, la pantalla grande terminó por vender los modernos ideales que se vivían en un glorioso - y completamente fabricado en un set de Hollywood, por supuesto- Estados Unidos; ideales que eran además exigidos por esta nación 
como requisitos indispensables para su participación en las distintas economías de los ávidos gobiernos que por entonces pululaban en América Latina —en el Perú, estaba al mando Augusto B. Leguía durante toda la década de 1920- y que requerían de los favores del vecino del norte. Más allá de las consecuencias políticas, el impacto cultural que tuvo sobre las urbes fue inmediato: el modo de vida moderno, the American way of life, era expuesto ante los maravillados ojos de un público masivo que lo asimiló sin reparos, y así como pegó el engominado peinado de Valentino entre los jóvenes, pronto también lo hicieron los ritmos norteamericanos, encabezados por el fox-trot, con sus aires melódicos frescos y sus vertiginosos movimientos de baile que tan bien caracterizaban a esos "años locos" de la década de 1920.

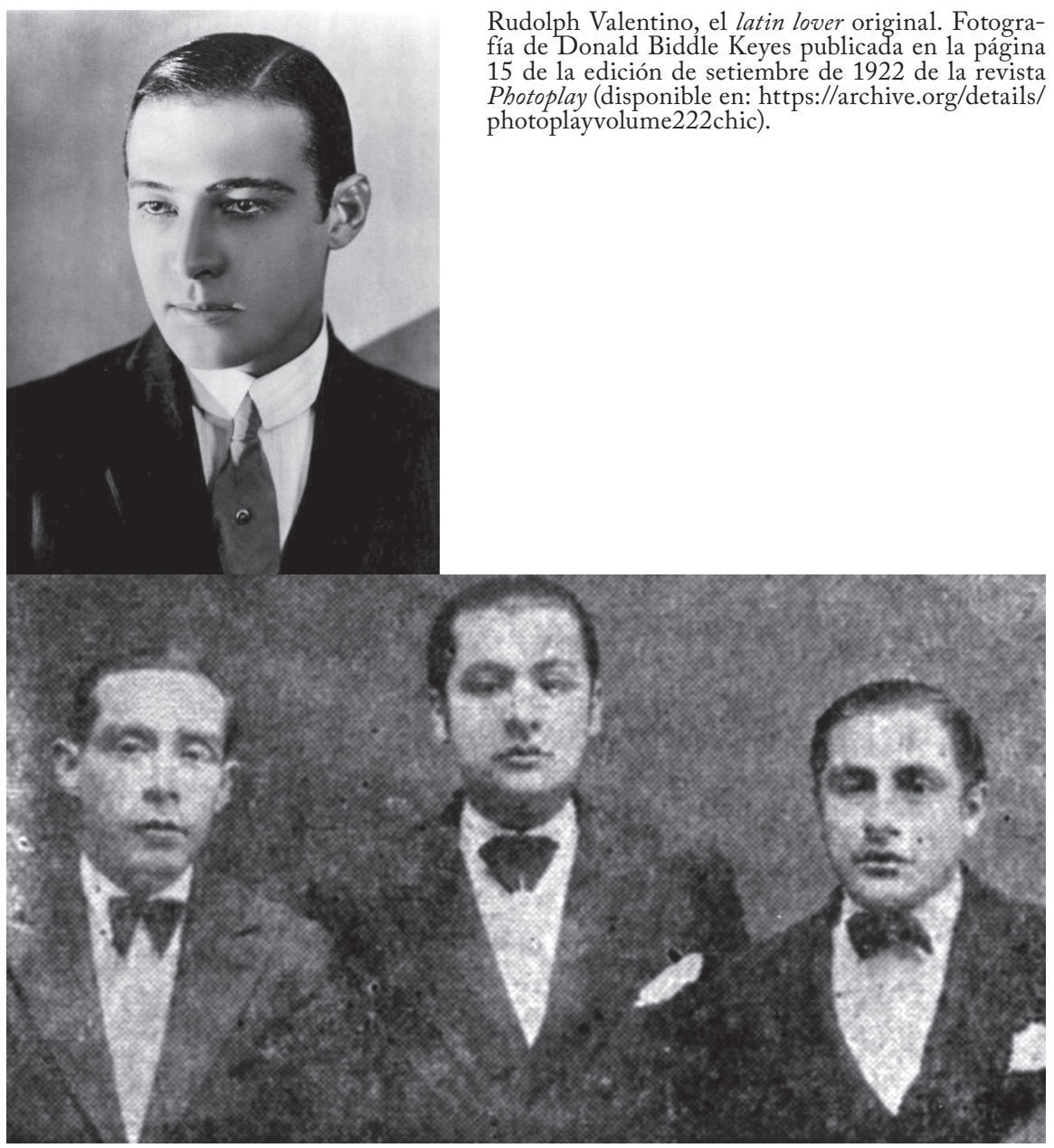

Trío Continental, conocido luego como Trío Americano (conformado por Felipe Pinglo y los hermanos Eugenio y José Díaz). Fotografía del Ministerio de Cultura del Perú (disponible en: http://www.cultura.gob.pe/comunicacion/noticia/ministerio-de-cultura-declaro-la-obra-musical-de-felipe-pinglo-alva-como). 
Pero, además de música, peinados y moda, Estados Unidos exportó el ideal del American dream - ese sueño americano de la casa con jardín y cerco blanco, de "triunfar sin importar de dónde provenías"-. Y sería ese ideal, justamente, el que perseguirían las clases populares del resto de naciones americanas y que las condujeron a encontrar una oportunidad de escape de esa territorialidad imaginada - concepto que plantea el geógrafo brasileño Haesbaert como dominio vivencial (2007, p.26) - en la que habitaban condenados a ser vistos como verdaderos migrantes en sus propias ciudades. ${ }^{3}$ Para alcanzarlo, "modernizarse" sería el mejor vehículo de salida que encontraron los miembros de las clases subalternas con el cual lograrían transitar desde esa condición de desterrados hacia su inclusión en la sociedad. De esa manera, el American dream no se restringía más a la soleada California; se trataba, ahora, de un sueño panamericano. Por supuesto, esa "modernización" implicó una serie de concesiones por parte de los sujetos de las culturas populares que se encontraban en las difusas y enfrentadas fronteras entre los imaginados territorios de marginalidad y centralismo — clásica situación del inmigrante, diría el sabio checo-brasileño Flusser-, que terminaron por sustituir su vieja realidad por una nueva que hicieron propia (Flusser, 2007, pp. 70-71).

Es así que el fox-trot se presenta como la vía perfecta para que el músico popular ingrese al mundo moderno. Pero no bastaba con repetirlo o interpretarlo; la apuesta por el nuevo ritmo requería que este sujeto popular se apropie de él y para ello el camino estaba en apropiarse de las letras, pasándolas del ininteligible inglés al español propio. Solo en ese momento, intérprete y oyente se validarían como realmente modernos y no como una mera imitación. El trueque de la lengua referencial por la lengua vernacular, ${ }^{4}$ entonces, será efectivo en esta empresa modernizadora. Ya no están restringidos a bailar la modernidad, ahora pueden.

\section{Cantando la modernidad}

Las posibilidades que tenía el músico popular para apropiarse de este nuevo género que reclamaba el público eran básicamente dos: la composición de fox-trots originales y la adaptación de fox-trots extranjeros. Para lo primero, era necesario aprender las reglas del género, tanto rítmicas como armónicas para recién poder proponer melodías nuevas que logren camuflarse, al menos musicalmente, entre las piezas foráneas tan de moda en la ciudad. Lo segundo implicaba, por su parte, apropiarse simple y directamente de esos éxitos norteamericanos que sonaban en la ciudad; esto es, pasar al español esas canciones en inglés. Sin embargo, durante la década de 1920, en América Latina, el acceso a la educación era todavía más limitado que hoy, y por tanto, no es de extrañar que la mayoría de músicos populares hayan estudiado a la justas algunos años en el colegio. La posibilidad de manejar un idioma extranjero estaba restringida aún mucho más 
y, aunque habría que revisar datos concretos de la época, estamos seguros de que no nos equivocamos al afirmar que estadísticamente, a nivel popular, casi nadie sabía inglés. ¿Cómo traducir de un idioma a otro si no se le entendía?

La clave para esta respuesta llegó dando vueltas, literalmente: las etiquetas de los discos. Como cuenta el Dr. Gérard Borras a propósito de su revisión de la historia de la música popular en Lima, "en un primer momento, los títulos de canciones aparecen con los timbres únicamente en inglés y después con títulos en inglés traducidos al español, señal de su "adaptación” al medio" (2012, p. 111). La información era mínima pero sustancial, puesto que ayudaría a los autores que escogían ceñirse a estos títulos conocidos y reclamados por el respetable para inspirarse en sus propias "re-creaciones".

Esta práctica fue común en toda Latinoamérica, con distintas versiones de las mismas canciones apareciendo a lo largo del continente en grabaciones y cancioneros. Revisemos, a modo de ejemplo, el fox-trot del prolífico autor estadounidense Clarence Gaskill, I'm wild about horns on automobiles that go "Tata-ta-ta!". Esta cómica pieza, grabada por primera vez en 1928 por Fred Hall (DAHL, 2018a), trata sobre un hombre que gusta mucho de las bocinas de los automóviles - por encima de las sirenas, de los Klaxon y hasta del blues- pues con ellas puede conquistar a las mujeres que antes no accedían a sus galanteos. Este fox tuvo una gran popularidad en su época; así, en Argentina aparece una edición de esa misma grabación de Hall a cargo de la empresa Veroton que traduce el título a "Estoy loco por bocinas de automóviles". 5 A continuación, la letra original en inglés y su traducción al español: ${ }^{6}$

\section{I'm wild about horns on automobiles}

Ev'ry body has a certain racket nowadays, I just got a funny one that keeps me in a daze. Some folks like the Op'ra and then others like the blues, but I like something diff'rent and here's the one I choose:

I'm wild about horns on automobiles that go "Ta-ta-ta-ta!"

I don't know what there is about one but you can't get a girl without one. I ain't had a girlfriend for many a night, since I got that bugle I'm doin' all right.

I'm wild about horns on automobiles that go "Ta-ta-ta-ta!"

\section{Me fascinan las bocinas de automóviles}

Todo el mundo tiene en estos días su propio estruendo, yo tengo uno gracioso que siempre me deslumbra. Alguna gente gusta de la ópera y a otros les gusta el blues, pero a mí me gusta algo diferente y esto es lo que escojo:

Me fascinan las bocinas de automóviles que hacen "iTa-ta-ta-ta!"

No sé qué es lo que tienen, pero sin una, no consigues chicas.

Hace muchas noches que no tenía novia, pero desde que tengo mi corneta, me va bien.

Me fascinan las bocinas de automóviles que hacen “iTa-ta-ta-ta!" 
Ever since I heard that horn

it's driving me insane,

I may feel all right

but, gosh, I'll never look the same.

You don't see so many people on the streets today,

the cars have run them over and they've all passed away.

I'm wild about horns on automobiles that go "Ta-ta-ta-ta!"

I'm glad I saved my dough to buy one, to be in style you ought to try one.

For Sirens or Klaxons the girls never fall but I get attention when they hear that call.

I'm wild about horns on automobiles that go "Ta-ta-ta-ta!"

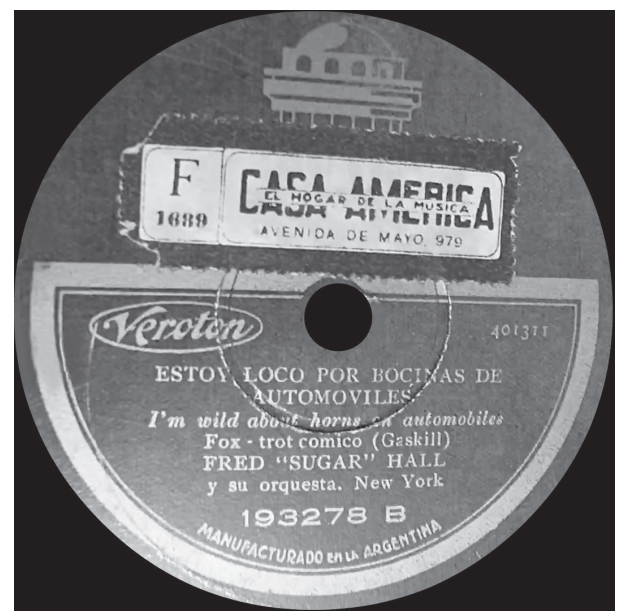

Desde que escuché esa bocina me estoy volviendo loco, puedo parecer bien pero, caray, nunca seré el mismo. No ves mucha gente en la calle hoy en día, los carros los han atropellado $\mathrm{y}$ todos se han muerto.

Me fascinan las bocinas de automóviles que hacen " $\mathrm{TTa}$-ta-ta-ta!"

Me alegra haber ahorrado para una, para estar en onda, tienes que probarla.

Por sirenas o Klaxon, no se mueren las chicas pero llamo su atención cuando me oyen. Me fascinan las bocinas de automóviles que hacen “ $¡ T a-t a-t a-t a ! "$

Etiqueta de edición argentina de la grabación de "I'm wild about horns on automobiles". Imagen tomada del video subido por Phonomono78s disponible en https://youtu. be/283XLN52aXM.

La popularidad de la canción inspiró una adaptación al español del letrista argentino Luis Rubinstein, grabada por Libertad Lamarque en 1930 (DAHR, 2018b), bajo el nombre de "Estoy loca por la bocina del automóvil" pero con una trama muy distinta donde la protagonista — primera gran diferencia con la original: el género del personaje protagónico - repara sobre la nostalgia que provoca no solo el amor perdido, "ideal, de cuerpo elegante y ojos sin igual", sino también la bocina del automóvil de este. Por otro lado, existe otra versión conocida en el Perú, atribuida por error justamente a Felipe Pinglo (Sarmiento, 2018, pp. 103-105) y conocida como "Loca por bocina de automobile", 7 con una letra que refiere también a un personaje femenino — sugiriendo una posible 
interpretación a partir de la versión de Rubinstein- pero que, en este caso, vive fascinada por el sonido de las bocinas, particularmente la del carro de su novio. Mostramos ambas versiones en seguida:

\section{Estoy loca por la bocina del automóvil}

$$
\begin{gathered}
\text { Yo tenía un novio } \\
\text { que era mi ideal } \\
\text { de cuerpo elegante } \\
\text { y de ojos sin igual. } \\
\text { En su lindo auto } \\
\text { con delirio me besó } \\
\text { y mientras, la bocina } \\
\text { mi oído acarició. }
\end{gathered}
$$

Qué lindo era oír el ronco gemir de aquel “¡Do-do-do-do!”. Sentir la boca de mi novio temblar sobre mis labios rojos.

Pero hace tiempo que mi amor no viene y echó al olvido mi pasión ardiente.

Ya nunca jamás tendré la dicha de oír “¡Do-do-do-do-do-do!”.

\section{Loca por bocina de automobile}

Yo me vuelvo loca

por bocinas de automobiles porque los oídos

me deleitan de verdad; ruidos y sonidos

ellas pueden imitar

y por eso es que me gustan una barbaridad.

De su auto mi amor me suele llamar así: “Ta-ta-ta-ta!”.

$Y$ yo sabiendo que me espera, de verlo busco la manera; y cuando su coche se lanza veloz, su amor él me jura con cálida voz y nuestro querer parece probarlo aquel “Ta-ta-ta-ta!".

$$
\begin{gathered}
\text { Hoy en Buenos Aires } \\
\text { todos tienen automobiles } \\
\text { y en bocinas reina } \\
\text { una enorme variedad } \\
\text { son graciosas todas } \\
\text { pero yo prefiero más } \\
\text { la del coche de mi novio } \\
\text { por su sonoridad }
\end{gathered}
$$

Fue así como de la locura por las bocinas que proponía el título original, refiriéndose al gusto por estas de un joven donjuán, se crearon dos historias distintas cuyo valor, más allá de los giros creativos que proponen cada uno de sus "traductores", residió en la capacidad que tuvieron de conectar con el público. Pero, más allá de la mención de un lugar familiar — como en el caso de la versión peruana- la recurrencia a temas contemporáneos que incluyen los todavía novedosos carros y su irrupción en la cultura popular, salones de baile, música de moda y conquistas amorosas, junto con el lenguaje fresco de sus versos, será lo que permitirá que estas adaptaciones gocen de la aceptación de la joven y exigente audiencia que optó por esa nueva producción local con la que finalmente lograban identificarse como "actuales y modernos". 
Felipe Pinglo, joven también, y comprometido con la escena local, no fue ajeno a este fenómeno y su apuesta por renovar el repertorio popular nacional lo llevó a escribir no pocas piezas que a ritmo de fox describían los ánimos despreocupados y el esplendor de una década dorada. No sorprende, pues, que casi la tercera parte de su producción haya estado dedicada a este novel género musical, y al menos ocho canciones parecen ser adaptaciones al español de éxitos norteamericanos: "Algo de día", "Dulce Susana", "Si una cinta hablada tuya tuviera”, "El sueño que yo viví”, "Hombre del sur”, "Seducción”, "Terroncito de azúcar" y "Vamos rodando".

\section{Entre la traducción y la creación}

Comencemos por el principio y el final de esta lista alfabetizada. Son coincidentemente dos canciones de las cuales no conocemos las versiones originales ("Algo de día" y "Vamos rodando"). De ambas sabemos que se trataron de arreglos de fox-trots de Felipe Pinglo, gracias a las notas que acompañan sus letras publicadas en El Cancionero de Lima, N.o 1128 y N.o 1130, respectivamente (García, 2016).

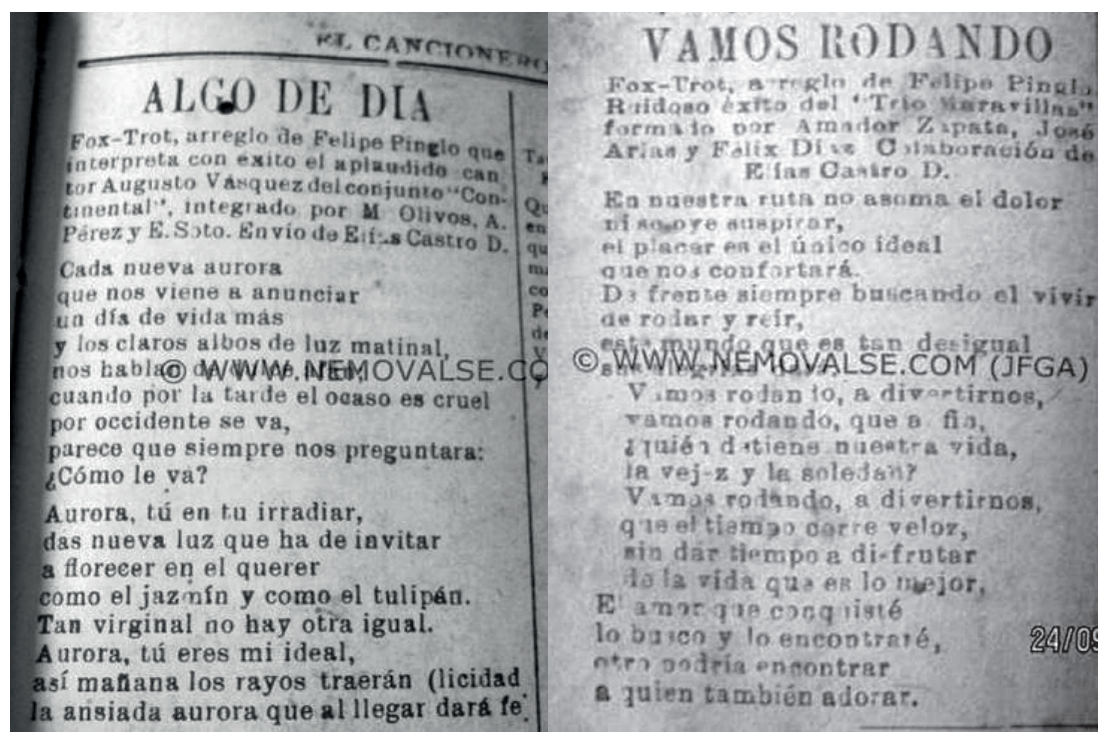

Letras de "Algo de día" y "Vamos rodando", publicadas en El Cancionero de Lima N.o 1128 y No 1130, enero de 1932 (Cuba y Arana, 2014, pp. 143, 274275). Colección de José Félix García Alva. 
Aunque no conocemos la versión original en inglés para poder hacer la comparación debida, vale la pena resaltar que a diferencia del resto de canciones de este grupo, la letra de "Algo de día" contiene más bien elementos típicos del estilo canónico de Pinglo, presente en los vals de su primer periodo: referencias a flores, epítetos y lenguaje preciosista (Sarmiento, 2018, p. 131). También conviene notar el juego con la palabra "aurora" y el nombre "Aurora", a quien le dedica los siguientes versos:

\author{
Algo de día \\ Cada nueva aurora \\ que nos viene a anunciar \\ un día de vida más \\ y los claros albos de luz matinal, \\ nos hablan de dulce afán; \\ cuando por la tarde el ocaso es cruel, \\ por occidente se va, \\ parece que siempre nos preguntará: \\ ¿Cómo le va? \\ Aurora, tú en tu irradiar \\ das nueva luz que ha de invitar \\ a florecer en el querer \\ como el jazmín y como el tulipán, \\ tan virginal, no hay otra igual. \\ Aurora, tú eres mi ideal; \\ así los rayos traerán \\ la ansiada aurora que \\ al llegar dará felicidad.
}

Por su parte, "Vamos rodando" presenta un estilo más acorde al grupo de canciones ligeras de Pinglo, además de confirmar su gusto por los carros, como se aprecia en sus fox-trots originales "Amor a 120" - "acelerado a fondo el corazón, la mano en el volante del amor..."- y "El volante" - "en Hudson Turismo, de máquina ideal, o en Limousine Cadillac, me deleita ir...”- . A diferencia de "Algo de día", de la cual la música parece haberse perdido, conocemos la melodía y acompañamiento de Vamos rodando gracias a la memoria del cantor chalaco Genaro Herrera en una grabación privada perteneciente a la colección del investigador Elías Arana. Presentamos a continuación la transcripción de la misma: 


\section{Vamos rodando}

Letra de Felipe Pinglo Alva en versión de Genaro Herrera Transcripción del autor
$\mathrm{Dm}$
G7
$\mathrm{C}$
G7

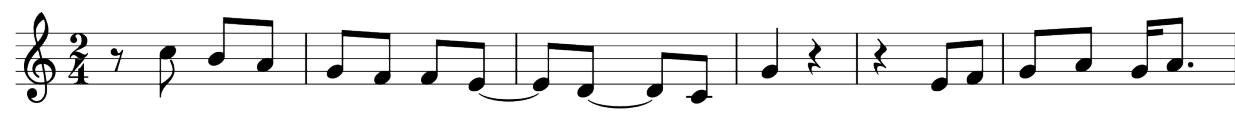

Ennues-tra ru-ta no/a-so

$\mathrm{ma} / \mathrm{el}-$ do - lor

ni se $\quad 0-y e / e l$ suspi -
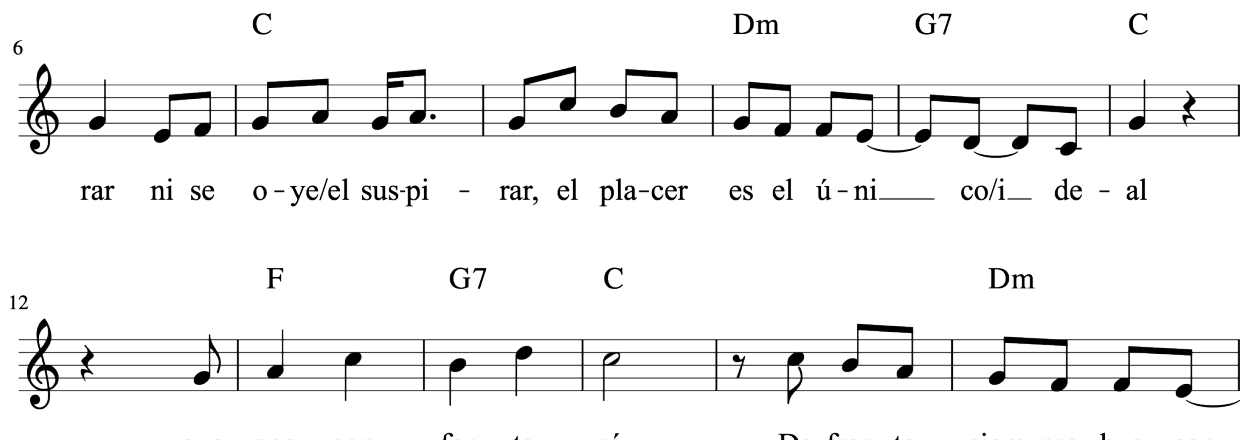

que nos con - for - ta - rá.

De fren-te siem-pre bus - can
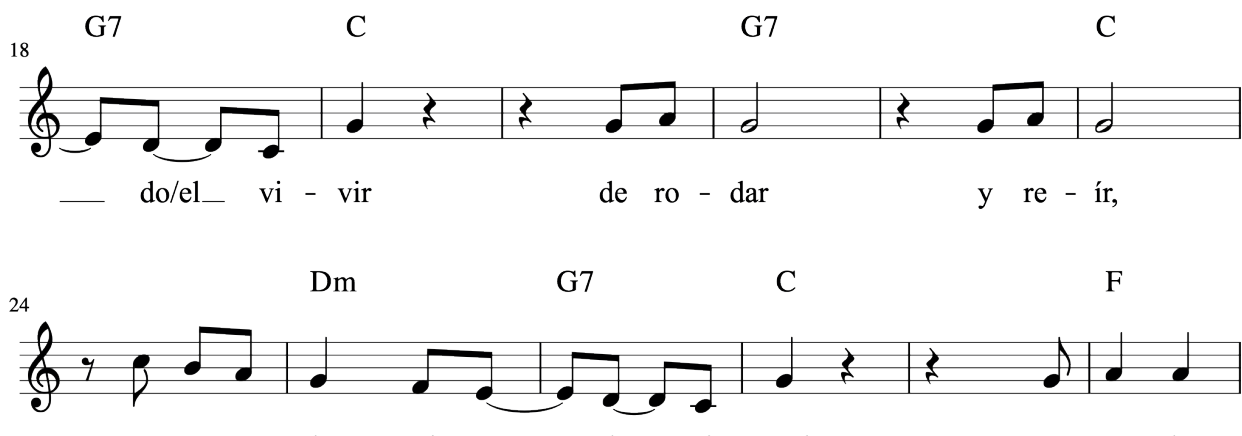

es - te mun - do que/es tan__ de_ si - gual sus a - le -

G7

$\mathrm{C}$

E7

Am

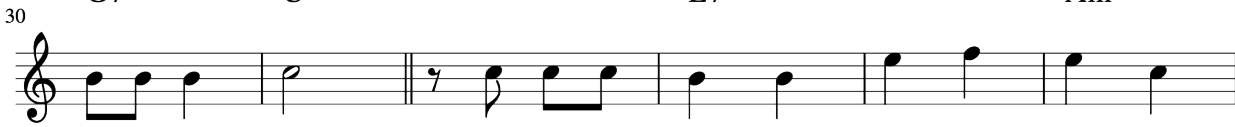

grí-as da - rá. Va-mos ro - dan - do/a di - ver - tir - nos,

$\begin{array}{lll}\text { A7 } & \text { Dm } & \text { G7 }\end{array}$

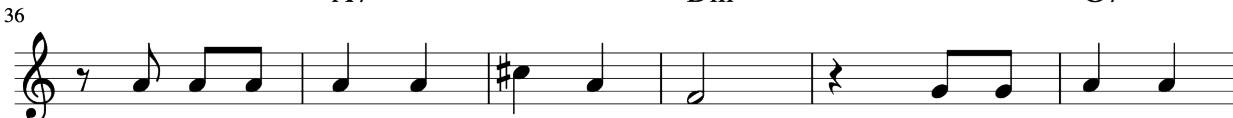

va-mos ro - dan - do que al fin, ¿quién de - tie - ne 

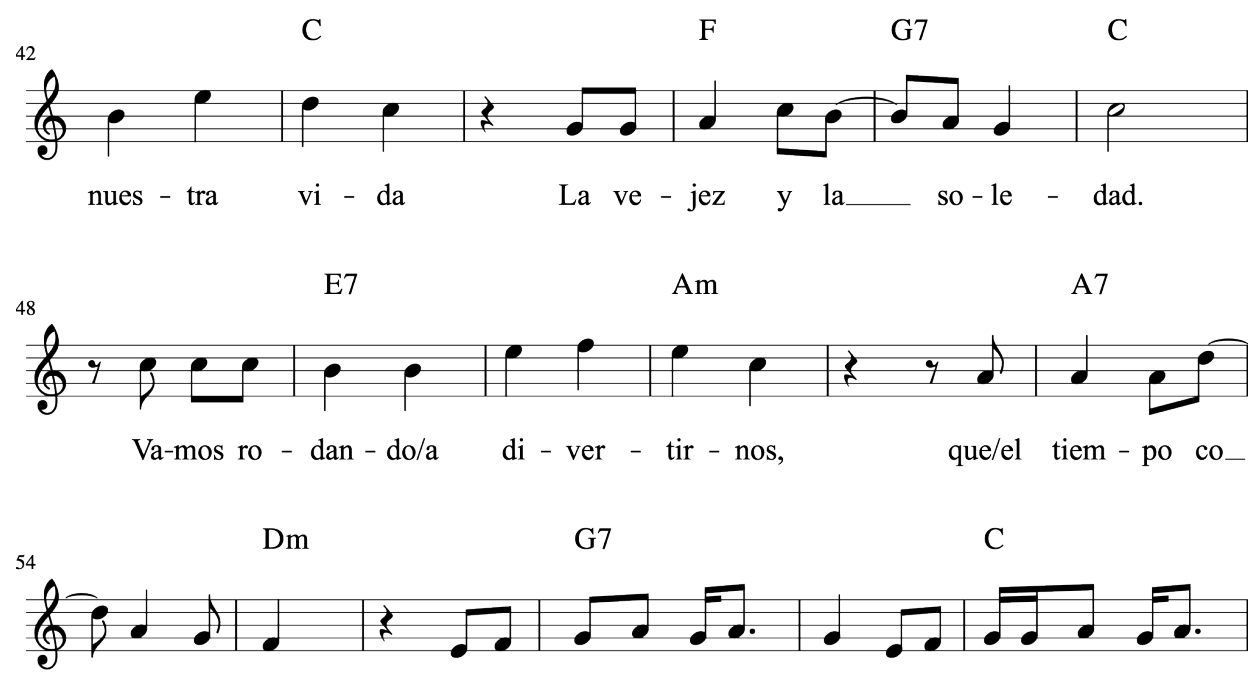

_re ve - loz sin dar tiempo/a disfru - tar de la vi-daque/es lo me -

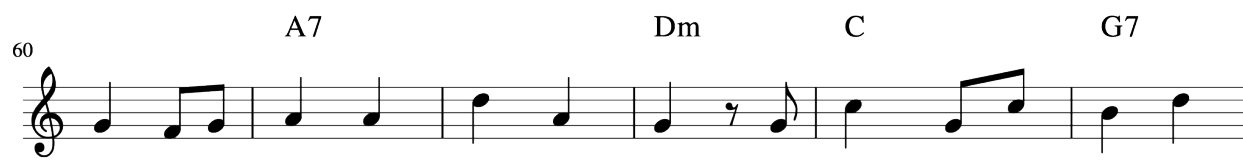

jor. El a - mor que con - quis - té, lo bus - co/ylo/en - con - tra -

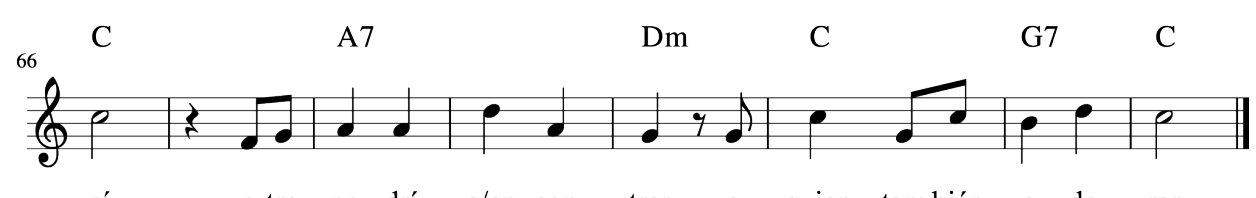

ré, - o-tro po-drí - a/en-con - trar a quien tam-bién a-do - rar.

Ilustración 5. Vamos rodando. Transcripción del autor. ${ }^{9}$

"El sueño que yo viví" representa una suerte de enigma dentro de la producción de Felipe Pinglo. Su historia es complicada: el título de esta canción se hizo conocido por haber sido consignado por error a otra adaptación al español del compositor que veremos después, Seducción, cuando fue grabada primero en 1969 por el Conjunto Fiesta Criolla y luego en 1986 por Las Limeñitas, en una producción de Óscar Avilés. Luego se haría pública la equivocación y se daría a conocer la letra de "El sueño que yo viví" de Pinglo; sin embargo, estamos por complicar todavía más la historia de esta problemática canción.

En 1929 fue estrenada una famosa película musical escrita por B. G. DeSylva, Lew Brown y Ray Henderson, Sunny side up. El tema principal de la cinta, "Keep your sunny side up", fue un éxito en América Latina y en el Perú 
fue adaptado por Pinglo con el título, justamente, de "Seducción". Pero junto a "Keep your sunny side up", pegaría otra canción llamada "If I had a talking picture of you”, cuya letra va así:

\section{If I had a talking picture of you}

I talk to your photograph each day, you should hear the lovely things I say, but I thought how happy I would be if your photograph could talk to me.

If I had a talking picture of you I would run it every time I felt blue,

I would sit there in the gloom of my lonely little room

And applaud each time you whispered "I love you; love you".

On the screen, the moment you came in view

we would talk the whole thing over, we two;

I would give ten shows a day and a midnight matinee

If I had a talking picture of you.

\section{Si tuviera una película sonora de ti}

Hablo con tu foto cada día, deberías oír las lindas cosas que le digo, pero pienso cuán feliz sería si tu foto me pudiera hablar.

Si tuviera una película sonora de ti, la vería cada vez que me sienta triste, me sentaría en la penumbra de mi pequeño cuarto y aplaudiría cada vez que suspires "Te amo, te amo".

En la pantalla, cuando aparezcas, hablaríamos todo de nuevo, tú y yo;

la proyectaría diez veces al día $y$ hasta en una matiné a media noche, si tuviera una película sonora de ti.

Las adaptaciones locales de la misma no tardaron en aparecer y al año siguiente fue grabada en español como Si tu imagen me hablara por el mexicano Tito Guízar (DAHR, 2018c) y por la Marimba Centro-Americana (DAHR, 2018d). Pero sería en Argentina donde una versión escrita por Manuel Del Olmo y grabada para la Victor en 1931 por Alberto Gómez exhibirá el título de "El sueño que yo vivo" (DAHR, 2018f). La letra de Del Olmo, a diferencia de aquella original del inglés que sueña con la posibilidad de tener una imagen animada y sonora (es decir, una película) de la mujer que ama el protagonista, trata nostálgicamente sobre la amada perdida que emergió en un sueño de amor. Pero lo curioso es que la versión que conocemos de Pinglo como "E1 sueño que yo viví", nada tiene que ver musicalmente con "El sueño que yo vivo" o con "If I had a talking picture of you". ${ }^{10}$ Una comparación entre las letras, tomando en cuenta las evidentes diferencias estructurales y métricas, permite rápidamente identificar que se trata de dos canciones distintas: 


\section{E1 sueño que yo vivo}

Surcaste el recuerdo del ayer, pura, tu visión conservo en mí que con tu hermosura, mujer, encarnas el sueño que viví.

Bello sueño de alegría y amores, bello sueño de caricias y ardores, hacia mí vino ideal, la mujer angelical toda envuelta en divinos rubores.

Fui feliz entre sus brazos tan bellos, me quemaron de sus ojos deshechos

y después huyó de mí y del loco frenesí

quedó solo el sueño que yo viví.

No podré olvidar a la que fue, luz que mi camino iluminó, para qué mi vida yo ofrendé y que sin piedad me abandonó.

\section{El sueño que yo viví}

Si yo tuviera una nena como en mis sueños forjé, pocas las horas serían para decir un querer y muy pegadito a ella al oído le diré:

"Encanto, divina nena, flor delicada de linda mujer, prenda de amor codiciada, nena adorada, me has de querer, dime que sí, preciosita, porque me matas por tu querer".

Bello sueño de alegría y amores, me embriagó con su perfume de flores, bello sueño que viví, el amor vino hacia mí y al marcharse dejó solo dolores.

Fui feliz besando labios tan rojos, me quemé con el mirar de tus ojos

y hoy siento cruel dolor, ahora que he perdido amor y que vuelvas pido yo con fervor.

Revisando el importante libro de César Santa Cruz sobre el vals criollo, en su capítulo dedicado a Pinglo, lista, entre otras canciones adaptadas al español, "If I had a talking picture", citando un fragmento de la letra que dice "si una cinta hablada tuya tuviera qué de cosas más..." (1989, p. 181), lo cual indicaría que existió, en efecto, una versión del compositor barrioaltino de esta canción, pero cuya letra se haya actualmente perdida. Esto significa, por otra parte, que "El sueño que yo viví" se trataría o bien de un fox original o de una adaptación de una canción que no hemos logrado ubicar y su título bien podría ser otro, si 
notamos, además, que la única relación entre el título y la letra de Pinglo sería la mención de la palabra sueño.

En la misma lista que hace Santa Cruz, ubicamos las últimas cuatro canciones que revisaremos y cuyas versiones originales conocemos. "Dulce Susana" se trataría de un fox-trot adaptado de "Sweet Sue, just you", escrita por Will J. Harris y Victor Young, grabada desde 1928 por múltiples artistas. Lamentablemente, de la letra solo nos queda el fragmento que Santa Cruz cita: "Eres tú, mi bien, mi única ilusión, sweet Sue, sweet Sue...” (1989, pp. 180-181).

"Seducción", como se explicó anteriormente, fue difundida como "El sueño que yo viví”, error que mantiene Santa Cruz (1989, p. 181). Se trata, pues, de una adaptación de la canción "Sunny side up" escrita por los mismos DeSylva, Brown y Henderson. La canción original, cuyo título hace una analogía entre el sol y las yemas de los huevos fritos y que fuera difundida en los mercados latinoamericanos como "Carta risueña" o "De buen humor" (DAHR, 2018f, $\mathrm{g})$, trata en realidad sobre el optimismo con el que hay que enfrentar las adversidades - con consejos tan entretenidos como que si tienes nueve hijos, ten en cuenta que un equipo de béisbol da plata - y poco tiene que ver con la letra que Pinglo propone. Veamos la letra del fox original:

\section{Sunny side up}

There's one thing to think of when you're blue: Hay algo en qué pensar cuando estás mal: there are others around much worse off than you!

If a load of troubles should arrive,

laugh and say "It's great to be alive!"

And keep your sunny side up, up,

hide the side that gets blue.

If you have nine sons in a row, baseball teams make money, you know!

Keep your funny side up, up, let your laughter come through, do!

Stand up on your legs, be like two fried eggs, keep your sunny side up!

\section{Lado soleado para arriba}

¡hay otros a tu alrededor mucho peor!

Si te ves con un montón de problemas, ríe y di "¿Qué bueno es estar vivo!"

Y mantén tu lado soleado para arriba, esconde el lado que está triste.

Si tienes nueve hijos, ¡sabes que los equipos de béisbol dan plata!

Ahora prestemos atención a la letra del fox de Pinglo, que contrariamente a la actitud optimista del musical, trata sobre un enamoramiento no correspondido: 


\section{Seducción}

Con ese tu cuerpo tan gentil ostentando siempre seducción, llevando prendidas al danzar sensuales miradas de pasión.

Ese cuerpo es de pecado $y$ en su ansiedad bacanal palpitando todo su ser porque siempre triunfará la mujer.

Y entre el gozar y el reír, agonizante de amor voy; soy un ideal que nunca pudo dar flor, nunca mi amor floreció.

"Hombre del sur" es otro fox cuya música había quedado en el olvido hasta que el investigador de música popular limeña, José Félix García Alva, dio con la pieza original norteamericana (García, 2016). Su letra apareció publicada en 1935 en La Lira Limeña y se trataría de un "arreglo literario" del fox-trot escrito por Rube Bloom y Harry Woods "The man from the south (with a big cigar in his mouth)”, grabado por el mismo Bloom en 1930 (DAHR, 2018h).

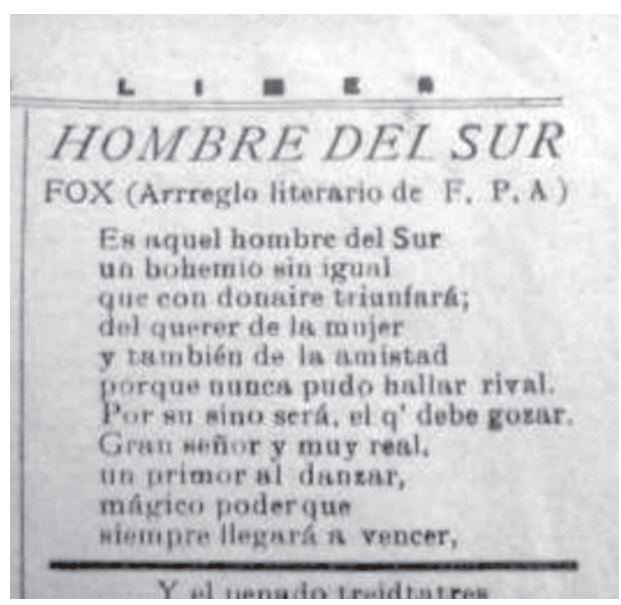

Ilustración 6. Letra de "Hombre del sur" publicada en La Lira Limeña, 1935. Colección de José Félix García Alva.

Este divertido fox describe a un gran hombre que atrae la atención de todo el mundo - comparándolo con los presidentes Hoover, Ford y hasta el príncipe de Gales - y de quien se dice literalmente viene del sur de los Estados Unidos de América y tiene siempre un gran cigarro en su boca. Leamos la letra original: 
The man from the south (with a big cigar in his mouth)

What's that cheering all about?

Why do all those people shout?

\section{E1 hombre del sur (con un gran cigarro en la boca)}

¿Qué es ese escándalo? ¿Por qué toda esa gente está gritando? ¿Oyen los martillazos sobre esas estacas?

No puede ser Hoover, tampoco Ford hacia donde todo el mundo corre.

It must be Lindbergh or the Prince of Wales. Debe ser Lindbergh o el príncipe de Gales.

Is that him passing by?

Say, folks, I know that guy!

He's a big, big man

from the south.

Yes, a great, big man

from the south.

He had a big cigar

in his mouth

so I know

that he comes from the south.
¿Es él quien está pasando?

¡Oigan, gente, yo lo conozco!

Es un grande, grande hombre

del sur.

Sí, un gran, grande hombre del sur.

tenía un gran cigarro

en su boca

y así es que sé

que viene del sur.

Otro será el hombre del sur que se presenta en la versión de Pinglo, un bohemio que triunfa en el amor y la amistad, en la misma línea de los personajes de otros fox-trots de su inspiración, como "Saltimbanqui" — escrito con Guillermo D’Acosta — o "Como un papá” — cuya música lamentablemente desconocemos—. Revisemos enseguida la letra de "Hombre del sur":

\section{Hombre del sur}

\section{Es aquel hombre del sur}

un bohemio sin igual

que con donaire triunfará

del querer de la mujer

y también de la amistad

porque nunca pudo hallar rival.

Por su sino será

el que debe gozar.

Gran señor

y muy real,

un primor

al danzar

mágico poder

que siempre

llegará

a vencer. 
Finalmente, existe una canción rescatada por la cantante limeña Teófila "Coco" Ramírez, que fuera esposa del también cantor Augusto Ballón, amigo íntimo de Felipe Pinglo. Ella grabó para el disco Memorias de Felipe Pinglo Alva-En el centenario de su nacimiento, editado por IEMPSA en 1986, "Terroncito de azúcar". La misma había sido identificada como una adaptación, también, por Santa Cruz en su mentado libro, mas se desconocía la versión original que habría inspirado esta adaptación de Pinglo. Se trataría, pues, de "Sugar (that sugar baby of mine)", canción de Maceo Pinkard, Edna Alexander y Sidney D. Mitchell, grabada para la Columbia en 1926 por Ethel Waters (DAHR, 2018i). En el fox-trot original, una mujer se enorgullece de su novio y del apelativo que le ha puesto ("azúcar") por ser este tan dulce como él:

\section{Sugar (that sugar baby of mine)}

Have you heard what I've done? Found a word, just the one that takes the place of one I used to call:

"Baby doll".

$$
\begin{gathered}
\text { It ain't new, } \\
\text { it ain't old } \\
\text { but if you do } \\
\text { what you're told }
\end{gathered}
$$

you'll find the answer if you take a look

in Mr. Webster's dictionary book:

The name is "sugar", I call my baby "my sugar", that is the reason why, maybe, that sugar baby is mine.

(I'm shoutin' 'bout him!) Funny, he doesn't spend any money, all he can lend me is honey that he can send anytime.

I'd make a million trips to his lips

if I were a bee 'cause they are sweeter than any candy to me.

\section{Azúcar (ese dulce amor mío)}

¿Te has enterado de lo que hice?

Encontré una palabra, justo una que reemplaza otra que solía emplear: "Muñequito".

No es nueva, tampoco es vieja pero si haces lo que te digo encontrarás la respuesta si buscas en el diccionario del Sr. Webster:

la palabra es "azúcar”, llamo a mi chico, "mi azúcar", esa es la razón por la que, tal vez, mi dulce amor es mío.

(¡Estoy gritando sobre él!) Gracioso, nunca gasta dinero, solo me presta miel que puede mandarme cuando sea.
Yo haría un millón de viajes hacia sus labios si fuera una abeja porque son más dulces que el caramelo ara mí. 
(That's why I'm sighin'...) Sugar,

I get my taffy from sugar,

what's more, I'm daffy 'bout sugar, that sugar baby of mine.

My sugar's so refined you can't find none like him in town; to make it more complete he's so sweet and so brown he's special ration.

$$
\text { "Sugar" }
$$

knows I'm just sweet on "my sugar", no, I won't cheat on "my sugar", that sugar baby of mine.
(Por eso suspiro...) Azúcar, consigo mi caramelo del azúcar, lo que es más, estoy loca por el azúcar, ese dulce amor mío.

Mi azúcar es tan refinada que no puedes encontrar a ninguno como él en la ciudad; para hacerlo aún más completo, es tan dulce y moreno que es una ración especial.

"Azúcar" sabe que soy dulce con "mi azúcar", no, no engañaré a "mi azúcar", ese dulce amor mío.

La adaptación de Pinglo no cuenta con los versos introductorios de la canción original y comienza a partir de la tercera estrofa, describiendo la típica historia de amor en donde la mujer solo quiere ser amiga del enamorado protagonista, revelando además un cambio de género de este, respecto al fox original:

\title{
Terroncito de azúcar
}

Rica, llena de dulces encantos cual terroncito de azúcar, mi nena así es.

\author{
Quiere \\ que sólo sea su amigo \\ pero es más fuerte el cariño \\ de mi corazón. \\ Y le quiero decir \\ mi sentir \\ para no sufrir \\ y también implorar \\ la pasión \\ de su corazón. \\ Oye, \\ tú, terroncito de azúcar, \\ préstame tu cariñito \\ y no sufriré.
}




\section{Conclusiones}

El fox-trot irrumpió en Latinoamérica a principios de siglo XX con una fuerza no experimentada hasta entonces, debida principalmente a las noveles y potentes industrias discográfica y cinematográfica que sirvieron como principal línea de comunicación de los valores que la cultura estadounidense requería exportar.

El cambio en los modelos de consumo y difusión de la música había producido una crisis entre los músicos populares, quienes, para sobrevivir, debían renovar no solo su repertorio, sino también, su misma cultura. La apropiación del nuevo ritmo sería el único camino para que los sujetos subalternos se apropien de la modernidad e ingresen a esa nueva sociedad. Para hacerlo, existían dos caminos: el primero, asimilar los elementos compositivos del estilo, rítmicos, melódicos y armónicos, para así poder proponer creaciones nuevas y originales que puedan clasificarse como fox-trots. El segundo, apropiarse de las canciones la misma que sonaban en los discos grabados en Estados Unidos a través de la adaptación de sus letras del inglés al español.

Más que traducciones, se trató de creaciones o acaso re-creaciones. En algunos casos, a partir de los títulos traducidos que aparecían en las etiquetas de los discos y en otros utilizando simplemente las melodías sobre las cuales planteaban nuevas letras. El éxito de estas canciones radicaría en el uso de un lenguaje moderno y fresco que retrataba perfectamente la época despreocupada que se vivía por aquellos años y la identificación que lograban las letras con los públicos locales. De esta manera, las voces extraterritoriales de las clases populares conquistaban para sí mismas un territorio que les había sido negado a pesar de pertenecerles.

Felipe Pinglo fue parte de la movida panamericana que reclamaba el lugar del músico nacional en la nueva industria. Así, en su obra encontramos adaptaciones de algunas canciones extranjeras: "Algo de día", "Dulce Susana", "Si una cinta hablada tuya tuviera", "El sueño que yo viví", "Hombre del sur", "Seducción", "Terroncito de azúcar" y "Vamos rodando". En estos fox-trots puede apreciarse otra faceta del autor, más libre y relajada, acorde a su juventud y el contexto que vivía la bohemia limeña por esos años de aparente esplendor y desarrollo. De esta manera, uno de los autores más canónicos de la música popular limeña terminaría mostrándose como uno de los más modernos, ya que gracias a su obra es que el cancionero nacional lograría apropiarse y enriquecerse no solo con estas adaptaciones y creaciones originales en particular, sino de todo un género que terminó por cambiar para siempre la música peruana y renovar la tradicional polca criolla. 


\section{Notas}

1. Se ha optado por generalizar distintos ritmos estadounidenses - como el fox-trot, onestep, shimmy, ragtime, charleston, cakewalk, etc.- bajo el nombre de fox-trot que es como posteriormente se popularizó y asimiló en América Latina. Santa Cruz advierte, no obstante, que en el Perú el fox-trot se trocó por el one-step "para suplir la casi total ausencia de polcas criollas" (1989, p. 186), probablemente debido a que el tempo y coreografía de estas con el one serían más cercanos.

2. Estudiados por Florencia Garramuño para el caso del tango y el samba en Argentina y Brasil, respectivamente (2007), y por Fred Rohner para el caso del vals en el Perú (2018).

3. Llama la atención, por ejemplo, cómo en Chile se ha explicado el éxito de los ritmos negros norteamericanos con razones de carácter étnico que se restringen a la novedad que difundieron "revistas musicales con bailarines negros" (Rondón, 2014, p. 57) de la síncopa y los efectos que esta genera en el baile "entre los chilenos" (González \& Rolle, 2004, pp. 506-507), desatendiendo que el mismo fenómeno no podría explicarse de la misma manera en el resto de países latinoamericanos con fuertes presencias de culturas negras, sin considerar, por otro lado, que la síncopa también es propia de la cueca que se baila en su país desde el siglo XIX.

4. Términos prestados de Deleuze y Guattari (1978, p. 39).

5. En la edición original de la empresa discográfica norteamericana OKeh, el título aparece traducido como "Me encantan las bocinas de los automóviles" (DAHR, 2018a).

6. Esta y todas las letras originales que se presentan fueron transcritas y traducidas por el autor.

7. Llama la atención el uso de la palabra en inglés automobile, cuya pronunciación correcta la convierte en una palabra aguda dentro de la letra en español.

8. No se referiría a la capital argentina si no a la plaza Buenos Aires, ubicada en el distrito de Barrios Altos, Lima, lugar de encuentro de la juventud a principios del siglo XX y donde quedaba el famoso cine Conde de Lemos.

9. Aprovechemos la partitura anterior para anotar elementos que caracterizan a la música popular estadounidense que tanto caló en nuestro acervo: frases rítmicas sincopadas, uso de la progresión armónica IIm-V7-I — representado en este caso por los acordes de re menor, sol sétima dominante y do mayor que acompañan el motivo inicial y cada comienzo de estrofa-, conocida como "cadencia dominante" y de muy común uso en los estándares de jazz, así como de dominantes secundarios, correspondiente a la sétima dominante, quinto grado del segundo, en los compases 37, 53, 61 y 68 .

10. Invitamos a escuchar el único registro conocido de El sueño que yo viví interpretado por Ricardo Panta y la Catedral del Criollismo en el siguiente enlace: https://youtu.be/lU$\mathrm{XNrYCCca8}$ 


\section{Referencias}

Avilés, Ó. (1986). El Gran Pinglo también compuso. Lima: IEMPSA.

Borras, G. (2012). Lima, el vals y la canción criolla (1900-1936). Lima: Institut Français d'Études Andines.

Conjunto Fiesta Criolla (1968). Evocaciones de Fiesta Criolla. Lima: Sono Radio S.A.

Cuba, C. \& Arana, E. (2014). Y vivirá mientras exista la vida. Recopilación de la obra del maestro Felipe Pinglo Alva. Lima: Edición del autor.

Discography of American Historical Recordings [DAHR] (2018a). OKeh matrix W401311. I'm wild about horns on automobiles (That go "ta-ta-ta") / Fred Hall; Sugar Babies. Disponible en http:/victor.library.ucsb.edu/index.php/matrix/ detail/2000210152/W401311-Im_wild_about_horns_on_automobiles_ That_go_ta-ta-ta.

DAHR (2018b). Victor matrix BAVE-60051. Estoy loca por la bocina del automóvil / Libertad Lamarque. Disponible en https://adp.library.ucsb.edu/index.php/ matrix/detail/800030628/BAVE-60051-Estoy_loca_por_la_bocina_del_automvil.

DAHR (2018c).Victor matrix BVE-59165. Si tu imagen me hablara/Tito Guizar. Disponible en https://adp.library.ucsb.edu/index.php/matrix/detail/800029890/ BVE-59165-Si_tu_imagen_me_hablara.

DAHR (2018d). Victor matrix BVE-58593. Si tu imagen me hablara / Marimba Centro-Americana. Disponible en https://adp.library.ucsb.edu/index.php/matrix/ detail/800029317/BVE-58593-Si_tu_imagen_me_hablara.

DAHR (2018e).Victor matrix BAVE-60770. Elsueno que yo vivo/Alberto Gómez. Disponible en https://adp.library.ucsb.edu/index.php/matrix/detail/800031230/ BAVE-60770-El_sueno_que_yo_vivo.

DAHR (2018f). Victor matrix BVE-55687. Sunny side up / Johnny Hamp; Kentucky Serenaders; Frank Luther. Disponible en http://victor.library.ucsb.edu/index. $\mathrm{php} / \mathrm{matrix} /$ detail/800026790/BVE-55687-Sunny_side_up.

DAHR (2018g). Columbia matrix W149049. Sunny side up / Ben Selvin and his Orchestra. Disponible en http:/victor.library.ucsb.edu/index.php/matrix/detail/2000038607/W149049-Sunny_side_up.

DAHR (2018h). Columbia matrix W149771. The man from the South (With a big cigar in his mouth)/Bayou Boys; Rube Bloom; Roy Evans. Disponible en https://adp. library.ucsb.edu/index.php/matrix/detail/2000039329/W149771-The_man_ from_the_South_With_a_big_cigar_in_his_mouth.

DAHR (2018i). Columbia matrix W141707. Sugar / Ethel Waters. Disponible en https://adp.library.ucsb.edu/index.php/matrix/detail/2000031471/ W141707-Sugar. 
Deleuze, G. \& Guattari, F. (1978). Kafka. Por una literatura menor. México D.F.: Ediciones Era S.A.

Faria, A.de (2011). Da Belle Époque à Era dos Jazz (cont. III). Uma História da Música de Porto Alegre. Disponible en https://www.sul21.com.br/colunas/2011/11/ da-belle-epoque-a-era-dos-jazz-cont-iii/.

Flusser, V. (2007). A língua brasileira. Bodenlos. Uma autobiografia filosôfica. São Paulo: Annablume.

Haesbaert, R. (2007). Território e multiterritorialidade. GEOgraphia, Año IX, N.o 17. Niterói: Universidad Federal Fluminense.

García, J. (2016). Fox-trot Hombre del sur - Felipe Pinglo adapta nueva letra en español a canción de moda. Nemovalse Blog. Interrogantes sobre el Vals(e) Criollo Peruano. Disponible en https://nemovalse.wordpress.com/2016/03/19/foxtrot-hombre-del-sur-felipe-pinglo-adapta-nueva-letra-en-espanol-a-cancion-de-moda/.

Garramuño, F. (2007). Modernidades primitivas. Tango, samba y nación. Buenos Aires: Fondo de Cultura Económica.

González, J. P. \& Purcell, F. (2014). Amenizar, sincronizar, significar: Música y cine silente en Chile, 1910-1930. Latin American Music Review, Vol. 35, N. 1. Austin: University of Texas Press.

González, J. P. \& Rolle, C. (2004). Historia social de la música popular en Chile, 18901950. Santiago: Ediciones de la Universidad Católica de Chile.

Rohner, F. (2018). La Guardia Vieja. El vals criollo y la formación de la ciudadania en las clases populares. Estrategias de representación y de negociación en la consolidación del vals popular limeño (1885-1930). Lima: Instituto de Etnomusicología de la Pontificia Universidad Católica del Perú.

Rondón, V. (2014). Música y negritud en Chile: De la ausencia presente a la presencia ausente. Latin American Music Review, Vol. 35, N.o 1. Austin: University of Texas Press.

Santa Cruz, C. (1989). El waltz y el valse criollo. Nuevas consideraciones acerca del valse criollo. Lima: Edición del autor.

Sarmiento, R. (2018). Felipe Pinglo y la canción criolla. Estudio estilístico de la ora musical Bardo Inmortal. Lima: Fondo Editorial de la Universidad Nacional Mayor de San Marcos - Facultad de Letras y Ciencias Humanas. 